\title{
Hydraulic Fracturing Characteristics and Stimulation Optimization of Tuffaceous Sandstone Reservoir in San Jorge Basin, Argentina
}

\author{
Li Xingchuan ${ }^{1,}$, Li Zhaohong ${ }^{1}$, Zhu Shanqing ${ }^{2}$ \\ ${ }^{1}$ Sinopec Argentina E\&P Inc., Buenos Aires, Argentina \\ ${ }^{2}$ Sinopec International Petroleum Service Corporation Argentina, Buenos Aires, Argentina
}

Email address:

xcli.sipc@sinope.com (Li Xingchuan)

${ }^{*}$ Corresponding author

To cite this article:

Li Xingchuan, Li Zhaohong, Zhu Shanqing. Hydraulic Fracturing Characteristics and Stimulation Optimization of Tuffaceous Sandstone Reservoir in San Jorge Basin, Argentina. International Journal of Energy and Power Engineering. Vol. 10, No. 1, 2021, pp. 1-9. doi: $10.11648 /$ j.ijepe.20211001.11

Received: February 16, 2021; Accepted: March 1, 2021; Published: March 4, 2021

\begin{abstract}
According to the post fracturing production performance characteristics of the operation wells in Sinopec Argentina work area of San Jorge basin, the more intensive the reconstruction is, the worse the effect is. By comparing the characteristics of typical wells, combining with the distribution characteristics of reservoir, the influence of tuffaceous matter, the state of in-situ stress, and the propagation law of hydraulic fractures, the main factors causing the abnormal performance are revealed. The characteristic parameters of typical wells in the work area are compared, and the main control factors affecting the key parameters of production are discussed. From the fracture scale, working fluid system, pumping parameters and other aspects, the targeted measures are optimized. The practice shows that the success rate of low intensity transformation is higher, which is nearly $10 \%$ higher than that of medium intensity transformation; within one year after fracturing, the average daily oil production of single well is $3.0 \mathrm{~m}^{3}$ higher, and the efficiency is remarkable. According to the characteristics of the work area, the small-scale and low-intensity sand adding transformation scheme is adopted, which improves the success rate and efficiency of hydraulic fracturing operation, and provides a new technical idea for tapping the potential of the next process.
\end{abstract}

Keywords: Hydraulic Fracturing Optimization, Stimulation Strength, Tuff Sandstone, Fracture Height Containment, San Jorge Basin

\section{Introduction}

The stimulation mechanism of hydraulic fracturing is to improve the bottom hole flow pattern and the reservoir fluid supply capacity through the sand packed or self-supporting fractures created by hydraulic fracturing. Therefore, for many years, the idea of "large amount of sand + large displacement + high sand ratio" has become the consensus of the industry to conduct a high-intensity fracturing technology with the purpose of increasing the fracture penetration ratio, expanding the oil drainage area and improving the reservoir development effect $[1,2]$.

The stimulation practice of Shengli Oilfield, Yanchang Formation reservoir in Ordos Basin, Liaohe Oilfield, an oilfield in Xinjiang, Hailaer Basin and other oilfields all showed that [3-8], within a certain range, there was a roughly positive correlation between post fracturing production and sand loading intensity, that is, the greater the sand loading intensity, the more obvious the effect of increasing production; then, with the increase of sand loading amount, the increase degree of production slowed down. Different oilfields had different optimal sand loading intensity, In different oilfields, the optimal sand loading intensity was different, mostly in the range of $2.0 \sim 2.5 \mathrm{~m}^{3} / \mathrm{m}$, in Sulige gas field it had even reached more than $10 \mathrm{~m}^{3} / \mathrm{m}$ [9].

However, in the stimulation practice of tuffaceous channel sand reservoir in San Jorge basin, Argentina, the opposite characteristics were shown, showing that the larger the sand adding intensity \& fracturing scale, the worse the post fracturing effect. The mechanism is worthy of further study. 


\section{Background of Geology and Reservoir Stimulation in Work Area}

San Jorge basin is a Mesozoic Cenozoic basin developed on the Paleozoic metamorphic basement. The project area is located in the south wing of the eastern stretch zone of San Jorge basin in Argentina, covering an area of $4069 \mathrm{~km}^{2}$. The main reservoir is Cretaceous Chubut group sandstone. In the middle and East of the work area, the main reservoir is the Canadon Seco/MDC formation; in the west, the Bajo barreal/Castillo formation corresponds to it; the Canadon Seco formation is subdivided into CS-1 and CO members.

The average porosity of reservoir is $14 \% \sim 23 \%$, the average permeability of low permeability layer is $21 \times 10^{-3} \mu$ $\mathrm{m}^{2}$, and the vertical permeability accounts for $15 \%$ of horizontal permeability $\left(\mathrm{k}_{\mathrm{V}} / \mathrm{K}_{\mathrm{H}} \leq 0.15\right)$. The formation pressure coefficient is low, only 0.93 (equivalent to formation pressure gradient of $0.092 \mathrm{MPa} / \mathrm{m}$ ), while the mud density used in drilling and cementing was in the range of $1.09 \sim 1.22 \mathrm{~g} / \mathrm{cm}^{3}$, which was higher than the reservoir pressure, so the invasion of drilling and completion fluid was inevitable. In addition, the rock wettability of the reservoir is hydrophilic, the original water saturation of the reservoir is high $(35 \% \sim 65 \%)$, the residual oil saturation is medium low, the two-phase flow interval is narrow, and the oil displacement efficiency of the reservoir is medium low; when the drilling fluid and operation fluid invade, it is easy to cause the water phase to be continuous phase, reduce the relative permeability of the oil phase, and cause reservoir damage.

With the characteristics of low permeability, low pressure

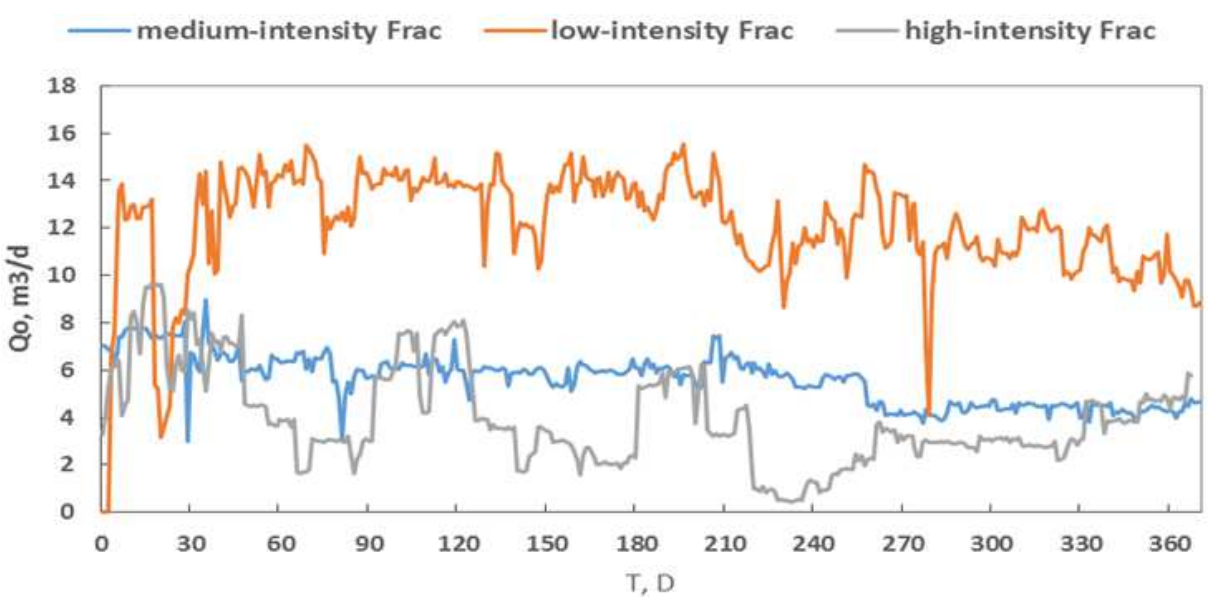

Figure 1. Post Frac performance comparison in different cases.

\section{Discussion on the Mechanism of Reservoir Stimulation Characteristics}

The formation mechanism of reservoir stimulation characteristics needs to be discussed by combining formation physical parameters, fracturing pumping parameters, hydraulic fracture parameters and post fracturing dynamic contrast analysis to lock in the key parameters that affect the production, and on this basis to explore the main control and easy to damage, hydraulic fracturing has become an important stimulation measure for oil companies in various oil areas within the basin since the 1990s [10].

During this period, various forms of technological transformation were implemented in the work area: type I was high-intensity sand loading fracturing, which was characterized by high displacement $\left(3.5 \sim 7.0 \mathrm{~m}^{3} / \mathrm{min}\right)$, large fluid volume (about $100.0 \mathrm{~m}^{3} / \mathrm{m}$ ) and large sand volume (generally more than $5.0 \mathrm{~m}^{3} / \mathrm{m}$ ); type II was medium-intensity sand loading fracturing, with sand loading intensity of $1.5 \sim$ $3.0 \mathrm{~m}^{3} / \mathrm{m}$ and fracturing fluid intensity of $20.0 \sim 50.0 \mathrm{~m}^{3} / \mathrm{m}$; The third type was low strength sand fracturing, with sand loading intensity less than $1.5 \mathrm{~m}^{3} / \mathrm{m}$, fluid intensity less than $20.0 \mathrm{~m}^{3} / \mathrm{m}$ and displacement less than $2.0 \mathrm{~m}^{3} / \mathrm{min}$.

The production performance of typical wells after fracturing (Figure 1) showed that (1) the effect of small-scale and low-intensity hydraulic fracturing (the same scale as clean fracturing fluid operation) was higher than that of medium-scale hydraulic fracturing; (2) the effect of medium-scale/intensity sand fracturing was better than that of large-scale sand fracturing in the past.

In the past, the main fracturing operations in the work area belonged to medium and high strength fracturing operations, and the success rate was only $81 \%$, and about $40 \%$ of the wells were difficult to add sand according to the design.

Therefore, it is an important basis for formulating targeted optimization measures to deeply explore the mechanism of sand loading difficulties and to lock in the key factors restricting the production effect after stimulation. 
For the medium and high intensity operation, the penetration depth was higher (the half length of the hydraulic fracture in the medium intensity operation in the work area was $81.5 \mathrm{~m}$, which was higher than the average $54.6 \mathrm{~m}$ half length of the hydraulic fracture in the low intensity operation well), and the oil drainage area of the oil well after the operation was larger; moreover, the formation coefficient value of the medium intensity operation layer was also higher than that of the low intensity operation well (Figure 2), and the production should be higher.

For the same low-intensity reconstruction operation well, the stimulation intensity, formation coefficient and oil saturation of well ME-CF were lower than those of well ME-GF (Table 2), but the liquid production and oil production were higher after fracturing (Figure 3).

Table 1. Well information in various Frac treatments.

\begin{tabular}{|c|c|c|c|c|c|c|c|c|c|}
\hline well & Thickness/m & $\begin{array}{l}\text { Sand loading } \\
\text { intensity } /\left(\mathrm{m}^{3} \cdot \mathrm{m}^{-1}\right)\end{array}$ & $\begin{array}{l}\text { Fluid loading } \\
\text { intestiy } /\left(\mathbf{m}^{3} \cdot \mathbf{m}^{-1}\right)\end{array}$ & $\mathbf{h}_{\mathrm{f}} / \mathbf{h}$ & $\mathbf{h}_{\mathbf{f}} \mathbf{L}_{\mathbf{f}}$ & $\begin{array}{l}\text { Pumpping } \\
\text { rate } /\left(\mathbf{m}^{3} \cdot \mathbf{m}^{-1}\right)\end{array}$ & Lf $/ \mathbf{h}$ & $\mathbf{W}_{\mathrm{f}} / \mathbf{m m}$ & remark \\
\hline EH-MF1 & 6.0 & 2.3 & 38.3 & 6.2 & 0.9 & 2.2 & 6.8 & 6.6 & \multirow{5}{*}{$\begin{array}{l}\text { Medium-intensity } \\
\text { guar gum sand } \\
\text { carrying fracturing }\end{array}$} \\
\hline EH-MF2 & 5.0 & 1.7 & 31.6 & 7.5 & 0.6 & 2.0 & 13.7 & 4.8 & \\
\hline EH-MF3 & 5.0 & 1.8 & 34.0 & 7.5 & 0.4 & 2.0 & 20.4 & 1.5 & \\
\hline EH-MF3 & 5.5 & 2.0 & 30.4 & 6.1 & 0.4 & 2.0 & 16.2 & 2.4 & \\
\hline MEN-MF1 & 8.0 & 1.7 & 31.9 & 2.7 & 0.3 & 2.4 & 7.8 & 7.4 & \\
\hline ME-CF & 6.0 & 0.4 & 6.7 & 5.6 & 0.5 & 2.4 & 11.0 & 1.0 & clean Frac \\
\hline ME-GF & 3.0 & 0.9 & 12.3 & 6.3 & 0.3 & 1.3 & 20.1 & 2.5 & Low-intensity \\
\hline ME-GF & 18.0 & 0.2 & 2.8 & 1.3 & 0.5 & 1.9 & 2.7 & 3.6 & guar gum sand \\
\hline ME-GF & 19.0 & 0.3 & 2.6 & 1.0 & 0.6 & 1.9 & 1.7 & 2.8 & carrying fracturing \\
\hline PC-LF1 & 8.0 & 7.1 & 115.1 & l & 0.9 & 6.4 & l & l & high-intensity \\
\hline EHa-LF1 & 17.3 & 1.8 & 29.5 & / & 0.6 & 3.8 & l & l & guar gum sand \\
\hline PCa-LF1 & 8.4 & 6.7 & 107.5 & 1 & 0.2 & 5.6 & 1 & 1 & carrying fracturing \\
\hline
\end{tabular}

Table 2. Petrophysics information of fractured wells.

\begin{tabular}{|c|c|c|c|c|c|c|c|c|}
\hline Well & Top/m & Bottom/m & Thickness/m & $\varphi$ & Sw & Vcl & $\mathbf{K} / \mathbf{m D}$ & Kh/(mD.m) \\
\hline EH-MF1 & 2515.0 & 2521.0 & 5.8 & 0.13 & 0.39 & 0.11 & 296.0 & 651.0 \\
\hline EH-MF2 & 2406.0 & 2411.0 & 2.9 & 0.13 & 0.63 & 0.08 & 1.9 & 0.3 \\
\hline EH-MF2 & 2338.0 & 2342.0 & 4.1 & 0.13 & 0.43 & 0.11 & 24.4 & 61.8 \\
\hline EH-MF3 & 2629.0 & 2634.0 & 4.4 & 0.13 & 0.35 & 0.11 & 897.8 & 2630.5 \\
\hline EH-MF3 & 2188.0 & 2193.5 & 8.2 & 0.13 & 0.58 & 0.10 & 31.3 & 118.6 \\
\hline MEN-MF1 & 1916.0 & 1925.0 & 12.2 & 0.15 & 0.54 & 0.14 & 285.7 & 1480.4 \\
\hline ME-CF & 1505.0 & 1513.0 & 3.5 & 0.05 & 0.70 & 0.21 & 0.4 & 1.3 \\
\hline ME-CF & 2340.0 & 2346.0 & 3.5 & 0.11 & 0.64 & 0.12 & 1.1 & 0.5 \\
\hline ME-GF & 2227.0 & 2230.0 & 3.4 & 0.16 & 0.45 & 0.16 & 21.7 & 56.3 \\
\hline ME-GF & 2335.0 & 2353.0 & 8.8 & 0.13 & 0.45 & 0.17 & 11.3 & 17.2 \\
\hline ME-GF & 2609.0 & 2628.0 & 8.5 & 0.10 & 0.53 & 0.18 & 2.6 & 3.2 \\
\hline PC-LF1 & 2041.0 & 2049.0 & 7.2 & 0.15 & 0.56 & 0.27 & 10.6 & 39.9 \\
\hline EHa-LF1 & 3085.7 & 3103.0 & 8.0 & 0.09 & 0.45 & 0.13 & 2.3 & 0.3 \\
\hline PCa-LF1 & 1807.0 & 1815.4 & 14.9 & 0.16 & 0.53 & 0.17 & 17.2 & 109.6 \\
\hline
\end{tabular}

- Sw XVd $\mathrm{Kh}$

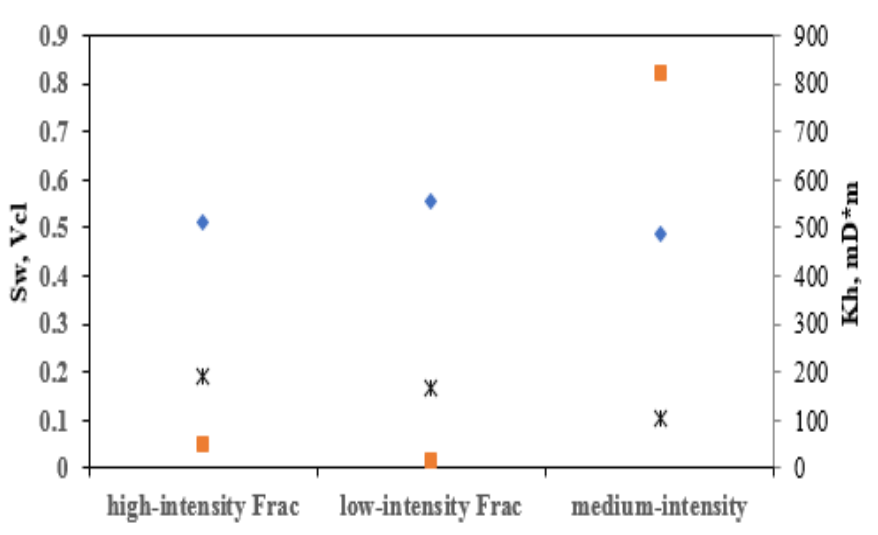

Figure 2. Statistical information of fractured wel.l

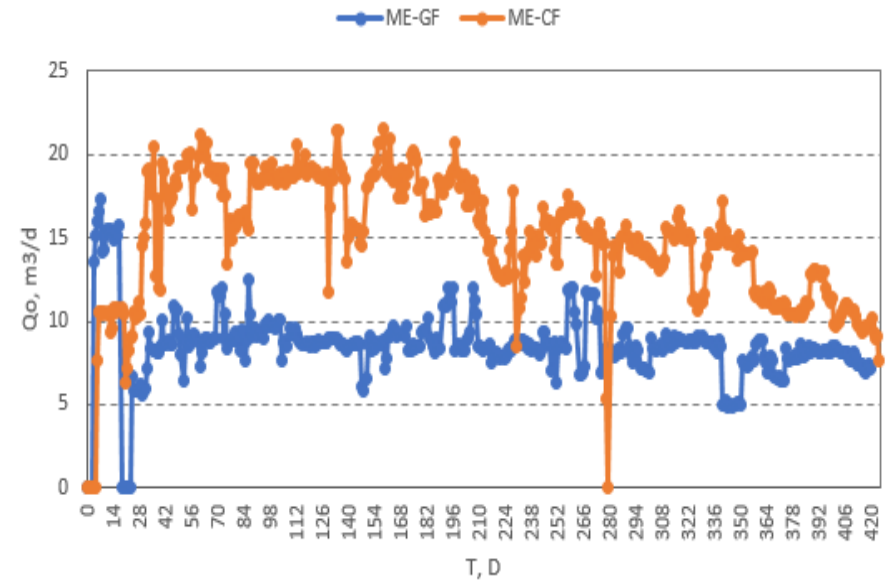

(a) Post frac liquid production between Well ME-CF and Well ME-GF 


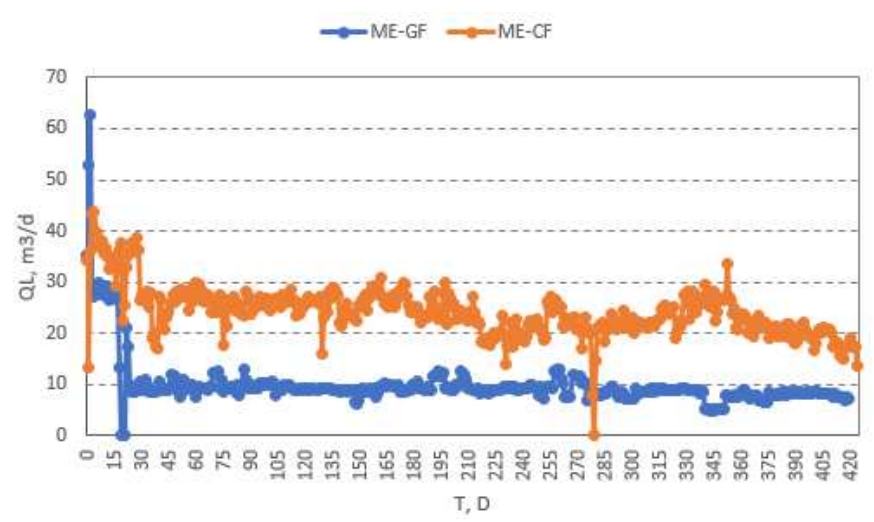

(b) Post frac oil production between Well ME-CF and Well ME-GF

Figure 3. Performance comparison between Well ME-CF and Well ME-GF at the similar scale.

According to the productivity evaluation theory of vertically fractured wells [11-14], the production of stimulated wells is positively correlated with fracturing scale (sand/fluid loading intensity/fracture length), formation coefficient and hydraulic fracture conductivity. While in SinopecArg work area the post-Frac production after is negatively correlated with fracturing scale and formation coefficient, which shows that fracture conductivity is the main influencing factor of production performance after fracturing.

According to the traditional theory, the main factors affecting the conductivity of sand packedd fractures include proppant embedding, sand concentration, proppant crushing and fracturing fluid residue retention. The first two factors affect fracture width, and the second two factors are related to fracture permeability [1]. The post fracturing performance of measure wells in the work area has shown a negative correlation with fracture width and sand concentration, which is inconsistent with the traditional theory. As for the residual fracturing fluid, because the field application is modified guar gum, the fracturing idea of "large displacement and high sand ratio" was proposed under the background of wide application of modified guar gum [15], which should not be the main reason for reducing fracture conductivity. All kinds of signs indicated that there should be other factors influencing the conductivity of sand filled fractures.

\subsection{Comparison of Characteristic Parameters of Typical Wells}

Among the typical well fracturing characteristic parameters (Table 1), the ratio of average fracture height to formation thickness (5.8) and the ratio of fracture half length to formation thickness (15.3) of medium strength sand addition wells are higher than those of low strength sand addition wells (3.6 and 8.6), indicating that the fracture occurrence may have an important impact on the permeability of hydraulic fractures.

The occurrence (orientation and length/width/height) of hydraulic fracture is related to the stress state of reservoir and surrounding rock [16-19], pumping parameters and working fluid viscosity $[20,21]$. The most ideal form of hydraulic fractures is to make fractures in the reservoir, that is, the length reaches the preset requirements, and the fractures are confined to the reservoir as far as possible in the longitudinal direction.

The penetration depth of hydraulic fracture in the target zone is generally determined by well pattern, reservoir distribution characteristics or planned single well control area. At the beginning of the project, the hydraulic fracturing design was relatively extensive, and the hydraulic fracture scale was designed based on $300 \mathrm{~m}$ well spacing. However, the subsequent study found that [22, 23]: for the channel sand reservoir in the work area, it is different from the domestic low-permeability reservoir dominated by gravity flow deposition of near source piedmont alluvial fan, underwater fan, alluvial fan and sublacustrine fan, which has the characteristics of wide range and large thickness; The sand bodies are mainly seasonal fluvial facies, mainly direct current channel sediments, while braided channel sands are relatively rare; the provenance direction is mainly the southern edge of the basin, and the channel sand bodies are mainly distributed along the north-south direction, the tortuosity of direct current channel is less than 1.23 , and the thickness of $82.9 \%$ sand bodies is $1 \sim 4 \mathrm{~m}$; there is a certain statistical law between the width and thickness of channel sand bodies, that is, $\mathrm{w} / \mathrm{T} \approx 30$.

According to the processing results of single well imaging data, the maximum horizontal principal stress direction is ne $87^{\circ}$, that is, when hydraulic fracturing operation is implemented, the hydraulic fracture cuts the river channel nearly vertically along the east-west direction, and it is easy to penetrate the river channel into tuffaceous mudstone, resulting in invalid filling of hydraulic fracture. Therefore, the previous method of designing fracture length according to well pattern conditions lacks sufficient basis.

The influence of tuffaceous could not be ignored in the study of the longitudinal propagation of hydraulic fractures. In the process of basin formation and evolution, there have been frequent volcanic activities in and around the basin, which caused the sedimentary system to be deeply affected by intermediate and acid tuffaceous matter, and its content gradually increased from east to west and from top to bottom $[24,25]$. The main rock forming mineral of intermediate acid volcanic rock is quartz [26]. Its large amount of doping in mudstone will cause the change of mechanical properties of surrounding rock, change the stress difference between mudstone and target layer, and affect the expansion of hydraulic fractures.

In order to deeply understand the influence of stress difference, 138 rock samples from 51 wells in 8 blocks were selected to carry out rock mechanics parameter experiments. The experimental results showed that the Poisson's ratio of sand /mud section was above 0.8 , and the young's modulus ratio of mud/sand section was above 0.7 (Figure 4). The approach of mechanical parameters meaned that the difference of in-situ stress between fracturing target layer and top and bottom layer decreased. The results of in-situ stress interpretation showed that the stress difference between reservoir and mudstone was about $3 \mathrm{MPa}$, which was not conducive to the control of hydraulic fracture height. Figure 5 
showed the hydraulic fracture propagation of well MEN-50GF before and after fracturing interpreted by acoustic scanning technology. The operation target interval was 1547.5 $\sim 1551.0 \mathrm{~m}$, and the test processing showed that the hydraulic fracture is $1534.0 \sim 1559.0 \mathrm{~m}$, the fracture height was $25 \mathrm{~m}$, and the longitudinal expansion of the fracture height was serious.

Fracturing calibration test analysis also confirmed this point. The test in this work area showed that about $66 \%$ of the wells belong to the situation of excessive fracture propagation in height [27], which was basically consistent with the monitoring results in the adjacent area [28, 29]. During hydraulic fracturing, the fracture mainly propagated longitudinally.

It can also be seen from the simulation results in Figure 6 that the hydraulic fracture not only expanded seriously in the longitudinal direction, but also maintained a high permeability, which could easily lead the clay minerals in the mudstone layer into the sand packed fracture in the reservoir, causing serious blockage, and greatly reducing the conductivity of the hydraulic fractures. Therefore, the operation effect of low-intensity modified well (ME-GF) with guar gum sand carrying operation is better than that of medium high-intensity/large-scale sand fracturing operation, which should be mainly related to the expansion degree of hydraulic fractures in mudstone; the more severe the vertical channeling of fractures, the faster the conductivity of sand packed fractures decreases, the higher the damage degree, and the greater the impact on production.

For guar gum sand carrying fracturing and clean fracturing fluid sand carrying operation of the same scale, the water saturation of clean fracturing fluid sand carrying operation well (ME-CF) was higher than that of adjacent well (ME-GF), porosity, permeability and formation coefficient were lower than those of adjacent well, but the operation effect was better than that of adjacent well. That was mainly due to two factors: the lower fracture height of clean fracturing fluid reduces the sand packed fracture in mudstone as a high-speed seepage channel to bring clay minerals into the sand packed fracture of reservoir, which was conducive to maintaining the high conductivity of sand filling fracture; the lower residue content and lower damage rate of clean fracturing fluid (about $20 \%$ of guar gum damage rate).

Even for the well stimulated with clean fracturing fluid, because its viscosity was only $20 \%$ of guar gum fracturing fluid, the simulation results of fracture propagation showed that the half fracture length and height were reduced by $7.5 \mathrm{~m}$ and $3.5 \mathrm{~m}$, respectively. On the other hand, it reflected the effect of fracture height on yield.

To sum up, the reservoir is narrow and thin, and the surrounding rock is rich in tuffaceous, which makes it easy for hydraulic fractures to penetrate the reservoir vertically and horizontally during fracturing operation. On the one hand, it causes invalid extension of fractures and increases the risk of sand screen out in operation; on the other hand, the clay minerals in the surrounding rock are easy to intrude into the reservoir along the packed hydraulic fractures, which seriously reduces the conductivity and permeability of hydraulic sand packed fractures, and consequently reduce the transformation effect. For the low scale stimulation, it can reduce the risk of energy dispersion and fracture narrowing caused by hydraulic fracture penetrating the formation, which is the fundamental reason why the success ratio of low-intensity Frac is higher than that of medium and high-intensity operation; on the other hand, it can reduce the damage caused by clay minerals in surrounding rock entering the reservoir along the hydraulic fracture, which is the reason why the effect of post fracturing is higher than that of medium and high-intensity operation. In addition, The remarkable stimulation effect of low-intensity clean fracturing showed the application potential of low viscosity and low residual sand carrying fluid in San Jorge basin.

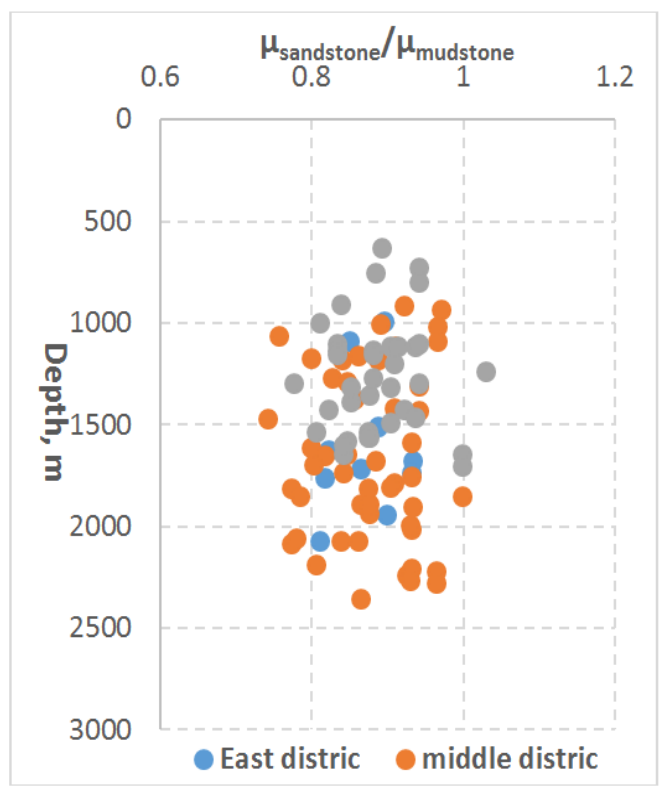

(a) Poisson's ratio of sand to mudstone

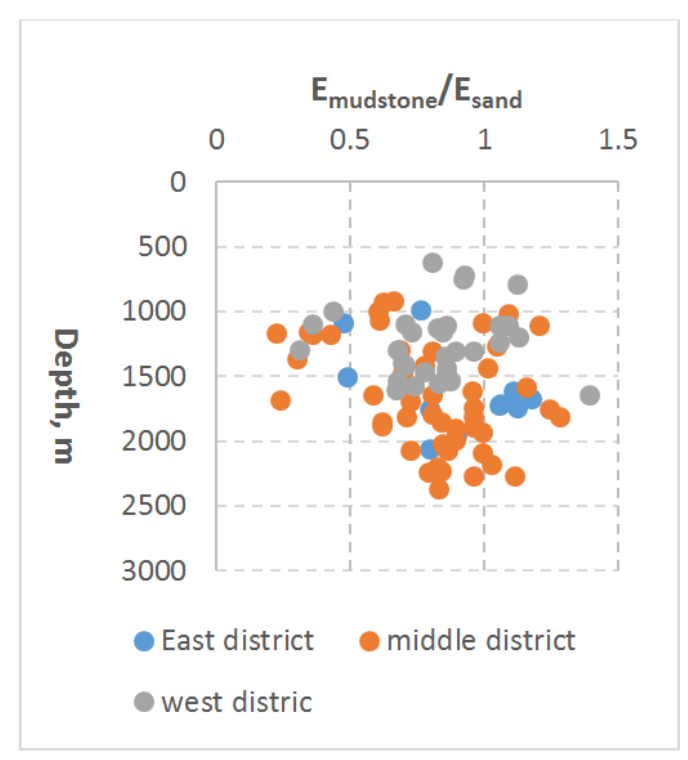

(b) Young's modulus ratio of mud to sand

Figure 4. The result of Rock mechanical parametric experiments 


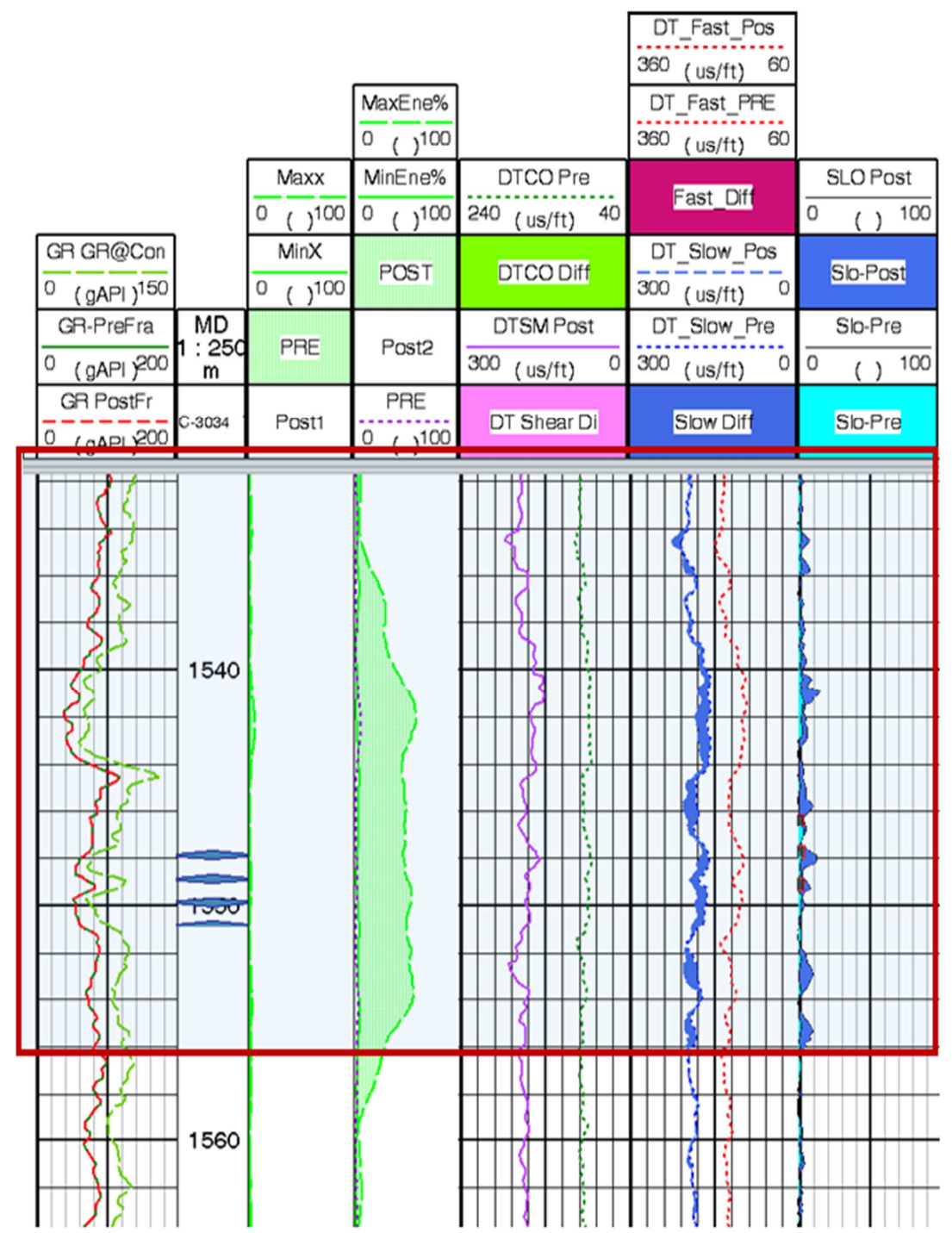

Figure 5. Detected Propped Fracture Height from 1534.0 to $1559.0 \mathrm{~m}(25.0 \mathrm{~m})$ based on the increase in cross energy and slowness anisotropy.

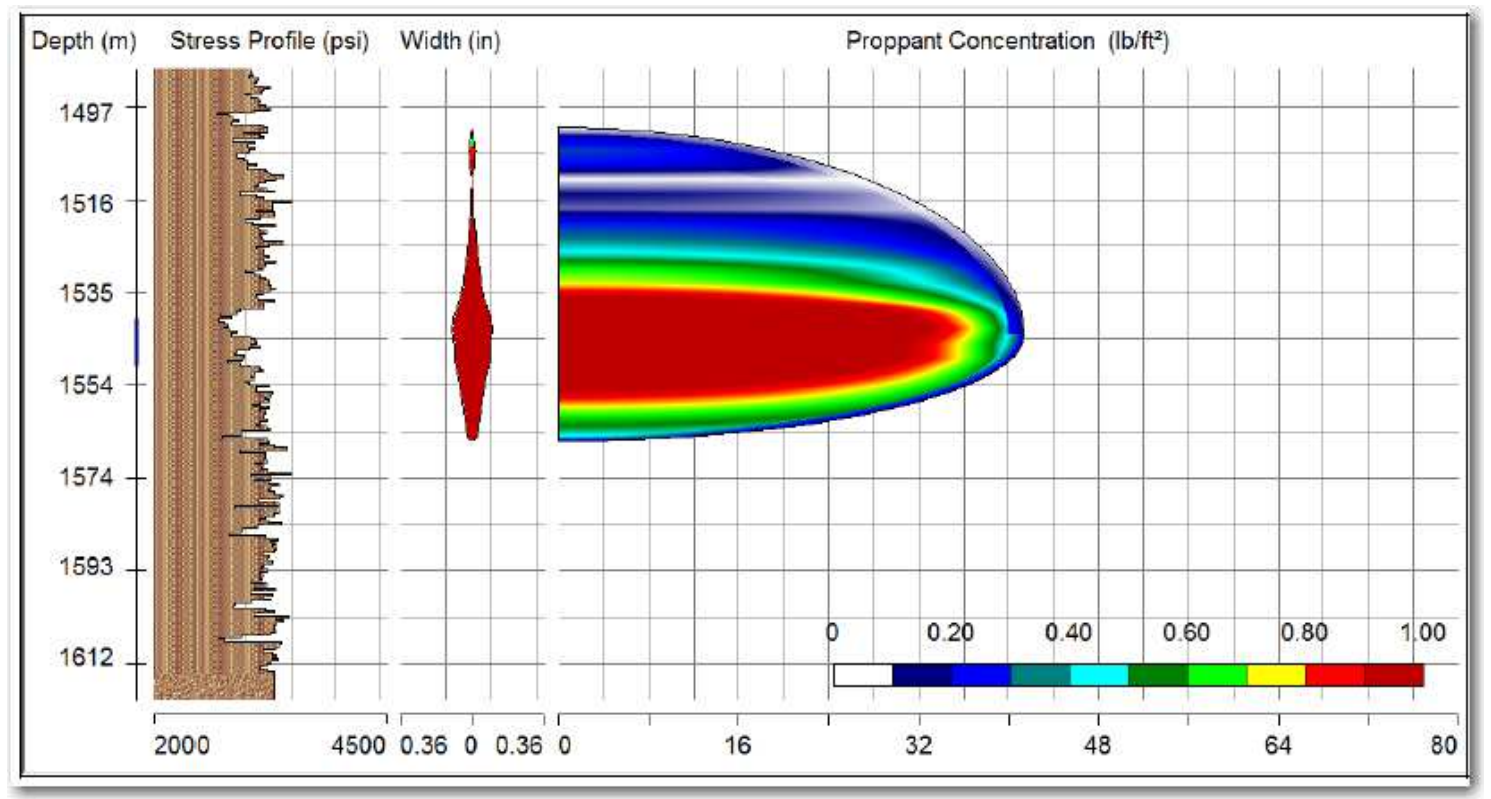

Figure 6. Simulated Propped Fracture Height of Well SPC-GF. 


\section{Effective Measures}

In view of the narrow and thin reservoir in the work area, the hydraulic fractures were easy to penetrate into the surrounding rock and expand, resulting in ineffective filling of sand packed fractures, the optimization of measures mainly was started from the fracture scale, working fluid system and pumping parameters, and the stimulation technology was mainly changed from medium and high intensity stimulation mode to low-intensity stimulation mode.

(1) According to the channel width corresponding to the reservoir thickness, the design length of hydraulic fracture was limited, and the half fracture length was not more than $1 / 3$ of the channel width;

(2) In terms of working fluid system, the amount of thickener is reduced by $20 \%$ to reduce the concentration of fracturing fluid; the amount of pad was reduced by nearly $50 \%$;

(3) The pumping rate was reduced from $2.5 \mathrm{~m}^{3} / \mathrm{min}$ to less than $2.0 \mathrm{~m}^{3} / \mathrm{min}$;

(4) The sand loading intensity has also been adjusted from $1.6 \mathrm{~m}^{3} / \mathrm{m}$ to $1.0 \mathrm{~m}^{3} / \mathrm{m}$, and even reduced to $0.75 \mathrm{~m}^{3} / \mathrm{m}$ in Castillo layer in the West.

Field practice showed that the optimized measures has achieved remarkable results (Table 3, Figure 7): (1) the success ratio of low intensity transformation process is higher, which is nearly $10 \%$ higher than that of medium intensity fracturing; (2) within one year after fracturing, the average daily oil production of single well was $3.0 \mathrm{~m}^{3}$ higher.

Table 3. Comparison of fracturing parameters between low and middle intensity stimulation.

\begin{tabular}{|c|c|c|c|c|c|}
\hline Type & Number of wells & Sand loading intensity $\mathrm{m}^{3} \cdot \mathrm{m}^{-1}$ & Liquid loading intensity $\mathrm{m}^{3} \cdot \mathrm{m}^{-1}$ & Success rate \% & Pumping rate $\mathrm{m}^{3} \cdot \mathrm{min}^{-1}$ \\
\hline Low-intensity Frac & 720 & 1.20 & 13 & 90.0 & 2.0 \\
\hline Mid-High intensity Frac & 476 & 1.61 & 26 & 80.8 & 2.4 \\
\hline
\end{tabular}

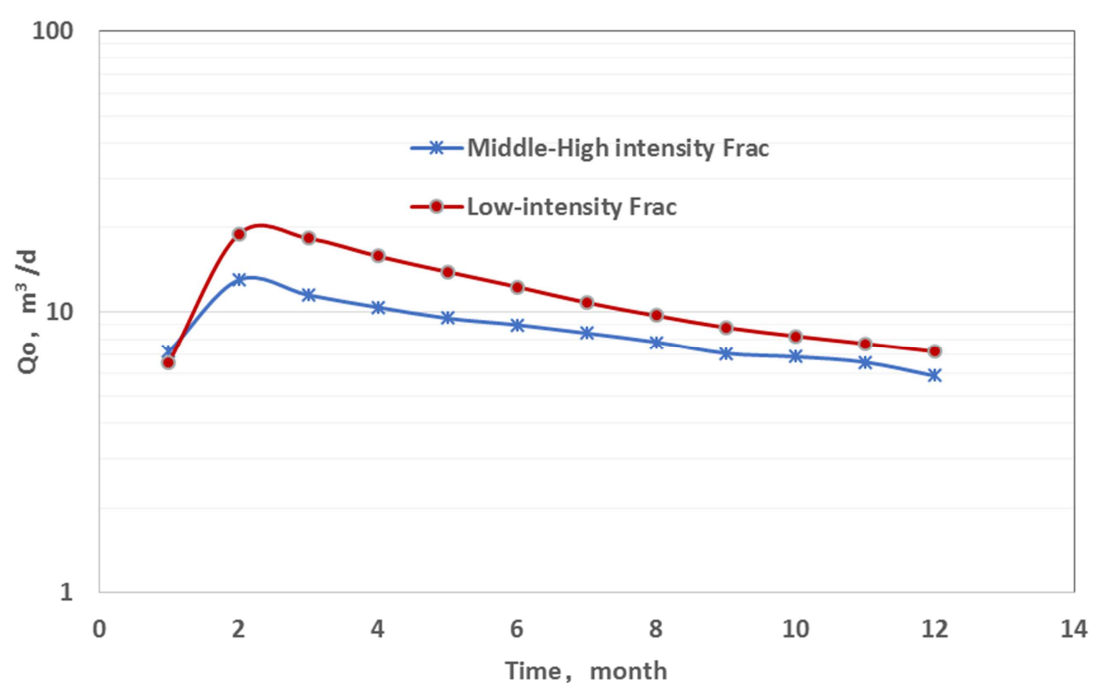

Figure 7. Comparison of Post Frac performance between low and middle instensity stimulation.

\section{Conclusion}

Combined with the comparative analysis of fracturing characteristics of typical wells, through the study of reservoir distribution characteristics, tuffaceous effect, in-situ stress state and hydraulic fracture propagation law in the work area, the main factors affecting the conductivity of sand packed fractures were revealed, the abnormal phenomenon of production characteristics of stimulated wells in the work area was effectively explained, the design and implementation of effective optimization measures were promoted, and remarkable results were achieved.

(1) The channel sand body in the work area is narrow and thin, which is distributed from south to north. The existence of tuffaceous can significantly reduce the stress difference between reservoir and surrounding rock.

(2) During the fracturing operation, the hydraulic fracture is easy to penetrate the channel sand body in the transverse direction and into the top and bottom mudstone in the vertical direction, resulting in the invalid pack of the fracture.

(3) In the past, the poor effect of medium and high-intensity sand fracturing was mainly due to the ineffective expansion of fractures, clay minerals in mudstone layer entered the sand packed fractures, which aggravated the damage to the conductivity of sand packed fractures.

(4) The small-scale and low-intensity sand loading stimulation reduced the expansion degree of hydraulic fracture to surrounding rock, and reduced the damage to the conductivity of sand packed fracture, so as to achieve higher process success rate and better operation effect. It was an effective reconstruction measure for the characteristics of the work area.

(5) The production increase effect of low intensity clean fracturing fluid operation was more significant, which 
revealed the application potential of low viscosity and low residual sand carrying fluid in San Jorge basin, and should be the main direction of the next process.

\section{Acknowledgements}

This work has been greatly supported by Li guien, Xing Qinghe, Liu Zhenxing, Zhang Gaojiu, fan Qingzhen and others in the process of development. I would like to express my gratitude.

\section{References}

[1] Wen Qingzhi, Zhang Shicheng, Li Lindi. Experimental research of long-term flow capacity of propping fractures in the low permeability oil reservoir [J]. Petroleum Geology and Recovery Efficiency, 2006, 13 (2): 97-99.

[2] Yan Huairong, Pu Sanlong, Wei Jiangwei, Zhang Qian, and Li Manwei. Study on high strength fracturing technology in Jiyuan Oilfield [J]. Petrochemical Industry Application, 2017, 36 (4): 84-88.

[3] Wu Baizhi. Research and application of key fracturing technology in low permeability reservoir of Shengli Oilfield [J]. Inner Mongolia Petrochemical Industry, 2010, 36 (24): 140-142.

[4] Li Guoxiong, Shi Fei, Liu Ding, Chen Xiangdong, Xu Moucun, and $\mathrm{Xu}$ Shaohua, et al. Study on fracture characteristics of Chang $4+5$ and Chang 6 reservoirs in Xiaojiahe district, Zichang Oilfield [J]. Shandong Chemical Industry, 2019, 48 (3) 80-82.

[5] Cui Xiantano, Ma Yusheng, Jiao Baofu, and Liu Suqin. Study on optimization of hydraulic fracturing parameters in extra low permeability oilfield [J]. Petroleum Drilling Techniques, 2001, 29 (5): 61-63.

[6] Wang Ling. Evaluation of fracturing effect and analysis of influencing factors of complex fault reservoir with low permeability and middle hole [J]. Unconventional Oil \& Gas, 2019, 6 (6): 95-99, 109.

[7] Lei Ruohuai, Guo Dali, Chang Jin, Xu Jiangwen, and Zhu Kai. The fracturing factors affecting the production of daily oil [J]. Journal of Chongqing University of Science and Technology (Natural Sciences Edition), 2013, 15 (4): 78-80, 97.

[8] Huang Youquan. Research on hydraulic fracture technologies for development of unconventional formations of Sudert region in Hailaer Oilfield [D]. Danqing: Daqing Petroleum Institute, 2007.

[9] Wu Xiaoli. Su Li Ge east area compression fracture craft optimization research [D]. Xi'an: Xi'an Shiyou University, 2010 .

[10] Da Prat G, Colo C, Martinez R, et al. A New Approach To Evaluate Layer Productivity Before Well Completion [J]. Spe Reservoir Evaluation \& Engineering, 1999, 2 (01): 75-84.

[11] Jiang Tingxue, Shan Wenwen, Yang Yanli. The calculation of stable production capability of vertically fractured well [J]. Petroleum Exploration and Development, 2001, 28 (2): 61-63.

[12] Wang Xiaodong, Zhang Yitang, Liu Ciqun. Productivity evaluation and conductivity optimization for vertically fractured wells $[\mathrm{J}]$. Petroleum Exploration and Development, 2004, 31 (6): 78-81.

[13] Huang Yong, Li Chunlan, Cheng Linsong, and Huang Shijun. A new method of estimating productivity of vertically fractured wells in low permeability oil reservoirs [J]. Petroleum Geology and Recovery Efficiency, 2010, 17 (1): 99-101.

[14] Prats M. Effect of vertical fractures on reservoir behavior-incompressible fluid case [J]. Society of Petroleum Engineers Journal, 1961, 1 (2): 105-118.

[15] Lu Yongjun. Recent advances of 90's foreign fracturing fluid technology [J]. Chemical Engineering of Oil and Gas, 1998, 27 (2): 115-118, 125.

[16] Daneshy A A. True and apparent direction of hydraulic fractures [J]. Society of Petroleum Engineers Journal. 1973, 149-163.

[17] Warpinski N R, Schmidt R A, Northrop D A. In-Situ Stresses: The Predominant Influence on Hydraulic Fracture Containment [J]. Journal of Petroleum Technology, 2013, 34 (3).

[18] Hottman C E, Smith J H, Purecell W R. Relationship among earth stresses, pore pressure, and drilling problems offshore gulf of Alaska [J]. Journal of Petroleum Technology, 1979, 31 (11): 1477-1484.

[19] Abou-sayed A S, Ahmed U, Jones A H. Systematic approach to massive hydraulic fracturing treatment design [C]. SPE 9877, 1981.

[20] Ge Yan. Three-dimensional simulation analysis of effect of process parameters on fracturing effect [D]. Dalian: Dalian University of Technology, 2018.

[21] Zhou Xiang, Zhang Shicheng, Ma Xinfang, and Liu Minfu. Research on fracture height containment in thin and poor pay zones [J]. Journal of Shanxi University of Science \& Technology (Natural Science Edition), 2015, 33 (4): 94-99.

[22] Carlos O L, Sergio R G. Unraveling multiple provenance areas using sandstone petrofacies and geochemistry: An example in the southern flank of the Golfo San Jorge basin (Patagonia, Argentina) [J]. Journal of South American Earth Sciences, 2016, 66 (1): 208-231.

[23] Paredes J M, Foix N, Pifiol F C, Nillni A, Allard J O, and Marquillas RA. Volcanic and climatic controls on fluvial style in a high-energy system: The lower cretaceous matasiete formation, Golfo San Jorge basin, Argentina [J]. Sedimentary Geology, 2007, 202 (1-2): 96-123.

[24] Sylwan C A. Geology of the Golfo San Jorge basin Argentina [J]. Journal of Iberian Geology, 2001, 27 (27): 123-158.

[25] Folguera A, Iannizzotto N. The lagos La Plata and Fontana fold-and-thrust belt: Long-lived orogenesis at the edge of western Patagonia [J]. Journal of South American Earth Sciences, 2004, 16 (7): 541-566.

[26] Hao Libo, Zhao Hongzhen, Lu Jilong, Zhao Yuyan, and Shi Yanxiang. The quantitative calculation method of the petrogenetic mineral content in intermediate-acid volcanic rock [J]. Acta Petrologica Sinica, 2006, 22 (2): 480-484.

[27] Li Xingchuan, Shang Huichang. Fracturing test characteristics analysis of tuffaceous sandstone in San Jorge basin, Argentina [J]. Well Testing, 2019, 28 (4): 1-6. 
[28] Huteau E D, BREDA E, HOMOVC J, et al. Stimulation with hydraulic fracture of an upper cretaceous fissured tuff system in the San Jorge basin, Argentina [C]. SPE 69586, 2001.

[29] Ghalambor A, Economides M J. Formation damage abatement: A quarter-century perspective [J]. SPE Journal, 2002, 7 (1): 4-13.

\section{Biography}

Li Xingchuan, male, born in 1971, is a doctor and senior engineer. He graduated from the structural geology major of the Institute of geology, China Seismological Bureau in 2007 and obtained a doctor's degree in structural fluid migration direction. Now he is engaged in the application of oil\&gas well engineering technology. 